\title{
Blaise Pascal, Pensieri
}

\section{Benedetta Papasogli}

\section{(2) OpenEdition}

\section{Journals}

\section{Edizione digitale}

URL: http://journals.openedition.org/studifrancesi/36022

DOI: 10.4000/studifrancesi.36022

ISSN: 2421-5856

\section{Editore}

Rosenberg \& Sellier

\section{Edizione cartacea}

Data di pubblicazione: 1 juillet 2005

Paginazione: 154-155

ISSN: 0039-2944

\section{Notizia bibliografica digitale}

Benedetta Papasogli, «Blaise Pascal, Pensieri», Studi Francesi [Online], 145 (XLIX | I) | 2005, online dal 30 novembre 2015, consultato il 19 avril 2021. URL: http://journals.openedition.org/studifrancesi/ 36022 ; DOI: https://doi.org/10.4000/studifrancesi.36022

\section{Questo documento è stato generato automaticamente il 19 avril 2021.}

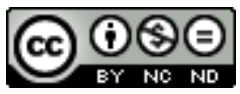

Studi Francesi è distribuita con Licenza Creative Commons Attribuzione - Non commerciale - Non opere derivate 4.0 Internazionale. 


\title{
Blaise Pascal, Pensieri
}

\author{
Benedetta Papasogli
}

\section{NOTIZIA}

BLAISE PASCAL, Pensieri, edizione con testo a fronte a cura di Carlo CARENA, prefazione di Giovanni RABONI, Torino, Einaudi, «Biblioteca della Pléiade», 2004, pp. 1093.

1 Ancora un'edizione italiana delle Pensées, su cui in primo luogo la particolare autorevolezza della sede editoriale attira l'attenzione. Si apre il volume con una curiosità in più, nel constatare che l'impresa della traduzione e dell'edizione non è stata condotta da francesisti italiani, o da filosofi versati negli studi pascaliani, ma da un umanista appassionato qual è Carlo Carena, e - sulla soglia del testo, con una breve presentazione - da Giovanni Raboni. È dunque un alveo inconsueto quello attraverso cui passa questa nuova e per certi aspetti decisiva opportunità d'incontro tra il pubblico italiano e Pascal, in un momento in cui tra i maggiori specialisti francesi è tuttora aperto il problema dell'edizione delle Pensées, e le ricerche filologiche raggiungono un'acribia che pure non impedisce nuove e coraggiose sperimentazioni (penso in particolare alla recente edizione proposta da Sellier nella collana "Agora" delle ed. Pocket, con criteri che rispondono insieme a una metodologia rigorosa e all'esigenza di favorire la "leggibilità" di Pascal presso un pubblico vasto).

Carlo Carena giunge alle Pensées dalla sua esperienza di traduttore di S. Agostino: si poteva pensare che l'edizione fosse giocata su larghe prospettive storiche, su affinità elettive intorno a temi culturali profondi. Si ha invece la sorpresa di costatare che proprio la problematica filologica ha polarizzato l'interesse dell'editore italiano. Da molti anni ormai in Italia Pascal appartiene ai filosofi più che ai filologi (con gl'inconvenienti che seguono alla mancata sintesi tra le due specializzazioni): questa Pléiade italiana è radicalmente in controtendenza: mai nessuno in Italia si era curvato con un così accanito amore, con tanta monastica pazienza, sul testo delle Pensées.

Dopo la prefazione di Raboni, brillante e rapida, la lunga introduzione di Carena immerge dunque il lettore nella filologia pascaliana. È ricostruita la storia del testo che 
ciascuno, nel corso di oltre tre secoli, ha contribuito a creare - a partire da un materiale così fragile che i contemporanei ne temettero la scomparsa - con criteri diversi. Ci si abitua a comprendere che non si può incontrare Pascal da solo a solo, ma sempre in compagnia dei suoi severi angeli custodi, che si chiameranno (ne cito solo alcuni) Bossut, Condorcet, Faugère, Michaux, Brunschvicg, Chevalier, Tourneur, Lafuma, Sellier, Le Guem... Vicini o lontani, questi mediatori prendono corpo. È con loro che si svolge il dibattito di Carlo Carena. Sono loro che l'editore italiano mette a confronto e che talora giudica, in forza di una consuetudine col testo pascaliano cui non sfuggono $\mathrm{i}$ dettagli del manoscritto, i problemi di trascrizione, le ragioni o l'arbitrio di un ordine.

4 Non è rispetto all'ordine dei frammenti che Carena porta un contributo nuovo. Egli adotta infatti sostanzialmente i criteri della prima ed. Sellier, intervenendo con spostamenti solo sui frammenti non riportati nella Copie di riferimento. Sul piano filologico, il notevole contributo di Carena è racchiuso e quasi nascosto in note siglate, leggere, che saranno apprezzate dall'occhio reso acuto dalla pratica delle edizioni critiche. Egli tratta infatti le diverse edizioni delle Pensées, almeno le più importanti, come une editore critico tratta le diverse fonti del proprio testo, collazionandole, rilevandone le varianti. Il lettore attento, sensibile all'enorme lavoro che soggiace a quella scelta di sigle potrà dunque costatare la diversità delle lezioni e non ignorerà nulla delle difficoltà di trascrizione, né delle sviste degli editori di Pascal.

Veniamo invece all'aspetto del volume che ha sul lettore l'impatto più immediato: la traduzione. Ce ne sono state tante di traduzioni di Pascal negli ultimi cinquant'anni, non di rado un po' affrettate, divulgatrici, oppure - come nel caso di Balmas per la Nuova BUR - probe e rigorose ma ineleganti. Carena offre un "bel" Pascal e insieme un Pascal vero. La traduzione è lungamente lavorata, affidabile, persino con qualche cura stilistica di troppo rispetto al duro "naturel" di Pascal. Siamo lieti di salutare un Pascal italiano degno di durare a lungo e di confrontarsi con le grandi edizioni francesi. Un solo rimpianto di fronte a questa Pléiade ineccepibile sotto il profilo filologico. Nessuno qui ci parla di Pascal in termini storico-critici, realizzando il delicato passaggio dalla filologia, alla filosofia, alla cultura letteraria. Non abbiamo, e ce ne dispiace, elementi di riflessione per fissare le coordinate di Pascal nell'"oggi" della cultura e della coscienza. 